\title{
A pandemia e o pandemônio: uma análise sobre os desdobramentos de informações falsas em tempos de Covid-19
}

\author{
Pandemic and pandemonium: an analysis on the displacements of false \\ information in Covid-19 times
}

\begin{abstract}
Bianca Cordeiro Manfrin
Universidade de Cruz Alta | Rodovia Municipal Jacob Della Méa, km 5.6 - Cruz Alta, Rio Grande do Sul, 98005-972 | Brasil | https://orcid.org/0000-0002-0916-2431 | bcmanfrin@gmail.com
\end{abstract}

\section{Dra. Veronice Mastella}

Universidade de Cruz Alta | Rodovia Municipal Jacob Della Méa, km 5.6 - Cruz Alta, Rio Grande do Sul, 98005-972|Brasil|https://orcid.org/0000-0003-1243-7667|veromastella@hotmail.com

Fechas | Recepción: 13/01/2021 | Aceptación: 26/02/2021

\begin{abstract}
Resumo
O presente artigo discute a fragilidade comunicacional na era da desinformação em uma crise humanitária, neste caso, a pandemia global da Covid-19. O estudo foi desenvolvido por meio de análise de conteúdo de notícias que relatam a circulação de informações inverídicas ou manipuladas sobre o coronavírus e que causaram desdobramentos negativos no período de março a dezembro de 2020. Para tanto, foram abordados conceitos comunicacionais, princípios deontológicos, contextos e reflexões sociais para melhor compreensão da problemática. A análise realizada neste estudo centrou-se em três episódios específicos: (1) a morte de mais de 700 pessoas no Irã por ingestão de álcool adulterado em decorrência do boato que a substância era a cura para a Covid-19; (2) o aumento de casos de ingestão e intoxicação por produtos de limpeza nos EUA após o
\end{abstract}

\begin{abstract}
This article discuss the communicational fragility in the era of disinformation in a humanitarian crisis, in this case, the global pandemic of Covid-19. The study was developed through news content analysis that reports the circulation of untrue or manipulated information about the coronavirus and that caused negative developments in the period from March to December 2020. For that, communicational concepts, deontological principles, contexts and social reflections are approached to better understand the problem. The analysis carried out in this study focused on three specific episodes: (1) the death of more than 700 people in Iran from drinking adulterated alcohol due to the rumor that the substance was the cure for the Covid-19; (2) the increase in cases of ingestion and intoxication by cleaning products in the USA after President Donald Trump suggested that the possible
\end{abstract}


presidente Donald Trump sugerir que as substâncias poderiam ser um possível tratamento para o coronavírus; (3) e a omissão de dados sobre o SARS-CoV-2 pela China no início da pandemia. Ambos os episódios serviram para ilustrar os perigos da desinformação, os tipos de desinformação existentes e a produção de danos a longo prazo que uma informação falsa pode causar. Com isso, o estudo reforça a importância de informações verificadas, bem como a pertinência do jornalismo nos tempos atuais e, assim, tem como pretensão contribuir para sua ressignificação.

Palavras-chave: desinformação, desinfodemia, Covid-19, deontologia jornalística. substances be a possible treatment for coronavirus; (3) and the omission of data on SARS-CoV-2 by China at the beginning of the pandemic. Both episodes served to illustrate the dangers of disinformation, the types of disinformation that exist and the long-term damage that false information can cause. With this, the study reinforces the importance of the verified information, as well as the relevance of journalism in the current times and, thus, it intends to contribute to its resignification.

Keywords: disinformation, disinfodemic. Covid-19, journalistic ethics.

\section{INTRODUÇÃO}

Atipicamente, estamos vivendo uma crise humanitária de saúde a nível mundial. A pandemia causada pelo SARS-Cov-2 instalou um cenário de insegurança e incertezas a respeito do futuro. Com estudos ainda precoces sobre o tratamento da doença, a Covid-19 vem gerando muitas especulações, polêmicas e teorias conspiratórias, o que resulta no compartilhamento de um grande volume de informações. Neste contexto, torna-se relevante abrir uma reflexão que vai além das pesquisas científicas sobre como prevenir ou combater o vírus, mas sim, uma análise dos processos comunicacionais sobre a doença. Em contextos excepcionais como este, os processos comunicacionais tornam-se ainda mais vulneráveis e imediatistas, de modo que, a população fica mais suscetível a conteúdos fraudulentos.

Por isso, estudos e debates sobre a problemática são extremamente necessários, uma vez que a desinformação toma novas proporções no século XXI, diante de um cenário comunicacional com tecnologias que permitem a "viralização" de conteúdos de forma acelerada, e muitas vezes, instantânea. Assim, a preocupação que surge na contemporaneidade é a facilidade, resultante do acesso à internet, que qualquer indivíduo tem de criar, compartilhar e adulterar informações, bem como, a velocidade de repercussão que esse conteúdo duvidoso pode ter em escala mundial.

Durante uma crise humanitária, a preocupação aumenta. Normalmente, são cenários de medo e turbulência, nos quais a população está lutando por sua sobrevivência, necessitando de recursos básicos, como comida, água, abrigo e assistência. Tão crucial quanto aparatos de subsistência, em situações de crise, é a informação. Nesta conjuntura, a disseminação de informações falsas pode colocar vidas em risco e gerar consequências irreversíveis.

Assim, o presente estudo analisa os desdobramentos de três episódios onde informações falsas, incorretas e manipuladas sobre a Covid-19 foram disseminadas na China, nos Estados Unidos e no Irã. O estudo foi desenvolvido por meio de uma abordagem qualitativa, com procedimentos metodológicos da análise de conteúdo de notícias, publicadas entre março e dezembro de 2020, 
que relatam os episódios escolhidos. Os episódios foram selecionados conforme os danos causados e sua progressão, a fim de ilustrar os tipos de desinformação e sua potencialidade, bem como elucidar as similaridades que a desinformação causa em países distintos. Além disso, o estudo apresenta uma reflexão sobre a importância dos processos de checagem, produção e socialização de conteúdos informacionais, de modo a evidenciar como o jornalismo tem um papel fundamental a desempenhar, cuja responsabilidade social pode ser um recurso para salvar vidas.

\section{A PANDEMIA}

Muitas pessoas confundem termos médicos para classificar a proliferação de uma doença em grande escala, como no caso das pandemias. Etimologicamente, a palavra "pandemia" tem origem do grego "pandēmía", e é formada pelo prefixo pan (todo), pelo radical demos (povo) e pelo sufixo ia (estado), assim, podemos dizer que pandemia, em tradução livre, é "aquilo que atinge todos os povos".

Empregada pela primeira vez no século IV a.C, por Platão, em sentido mais genérico, a palavra pandemia era utilizada para referir-se a qualquer acontecimento capaz de alcançar toda a população. Foi o médico romano, Galeno, quem trouxe a noção de doença para a palavra no século II d.C., ao utilizar "o adjetivo pandêmico em relação a doenças epidêmicas de grande difusão" (Rezende, 2004, p. 154). Todavia, a incorporação definitiva do termo pandemia ao glossário médico firmou-se apenas no século XVIII. Para Rezende (2004, p. 154), o conceito moderno de pandemia é o de uma epidemia de grandes proporções, ou seja, pandemia é o avanço de um surto que excede os limites locais e regionais e passa a ser continental e/ou mundial.

Em dezembro de 2019, a cidade de Wuhan, província chinesa, registrou os primeiros casos de Covid-19, doença causada pelo vírus SARS-Cov-2, o qual apresenta-se em curso como uma nova manifestação do grupo coronavírus. Com alto potencial de transmissão não demorou muito para outros países além da China registrarem casos de infecção. Desse modo, no dia 11 de março de 2020, a Organização Mundial de Saúde declarou pandemia global ${ }^{1}$. Contudo, a falta de compreensão sobre a gravidade da situação e a impaciência da população, frustrou os resultados de controle do vírus, prolongando a pandemia e abrindo brechas para novos surtos em regiões já recuperadas.

Até meados de novembro de 2020, o número de infectados por coronavírus passava dos 60 milhões, totalizando quase 2 milhões de óbitos. Contudo, a pandemia não assola somente questões sanitárias, mas também econômicas em escala global, de modo que inseguranças e incertezas fazem parte da rotina da maioria da população mundial. A recessão, o desemprego e a desigualdade social juntamente com a falta de assistencialismo e informações precisas sobre a origem do vírus, sua progressão e seus obituários, além da instabilidade sobre possíveis tratamentos e imunizações, projetaram um cenário caótico no mundo todo. É neste cenário que a pandemia se transforma em pandemônio, e aí outro vírus se prolifera: a desinformação.

\footnotetext{
${ }^{1}$ G1. (2020, 15 de março). Últimas notícias de coronavírus de 11 de março de 2020. G1. https://bityli.com/QDoZO. Consultado em 17 de março de 2020.
} 


\subsection{O pandemônio}

No dicionário Aurélio, a palavra "pandemônio" é classificada como um substantivo masculino que quer dizer confusão, balbúrdia. Na etimologia, a palavra tem origem idem ao grego: pan (todo) + daimon (demônio), entretanto, foi filtrada pelo latim "pandemonium", cuja origem é literária e cunhou-se pelo poeta inglês John Milton em sua obra "Paraíso Perdido", datada em 1667. Assim, o substantivo "pandemonium" foi um termo utilizado pelo autor para nomear o centro administrativo do Inferno. Com o passar dos anos, a palavra foi ressignificada ao sinônimo de desordem.

Navegar pela etimologia de ambas palavras, traduz um outro tipo de caos e de virulência a qual a UNESCO descreve como desinfodemia ${ }^{2}$, uma pandemia paralela à Covid-19, que é a desinformação disseminada sobre a doença. Assim, a palavra "pandemônio" faz jus ao que Wardle e Derakhshan (2017) classificam como "information disorder", uma desordem de informações. O termo foi cunhado como uma alternativa à terminologia "fake news", uma vez que a maioria dos conteúdos fraudulentos nem sequer se disfarça de notícia. Isso ocorre porque notícias significam informações verificáveis de interesse público, e as informações que não atendem a esses padrões não merecem o rótulo de notícias. (Berger, 2019, p.7). No meio digital, por exemplo, o fenômeno se manifesta através de memes, vídeos, imagens ou atividades coordenadas nas redes sociais, como hashtags e boots. Além disso, boa parte desses conteúdos não são essencialmente falsos, podendo ser enganosos, ou frequentemente, genuínos, mas tirados de contexto para fins ocultos.

Ao analisar o fenômeno da desinformação, Claire Wardle e Derakhshan (2017), apresentam um quadro conceitual de "desordem informacional", onde identificam três dimensões de informações falsas: "misinformation", "disinformation" e "malinformation. A informação incorreta (misinformation), ocorre quando informações falsas são compartilhadas sem o objetivo de causar danos, por exemplo, erros não intencionais como fotos, dados, estatísticas e traduções imprecisas; a desinformação (disinformation) é quando informações falsas são conscientemente criadas e compartilhadas com o intuito de causar danos, podendo enquadrar a manipulação de informação; e por fim, a má-informação (malinformation) que acontece quando informações genuínas são compartilhadas e/ou tiradas de contexto para causar danos. Aliada a modernas tecnologias que ampliam e facilitam a produção e difusão de conteúdos inverídicos, a desinformação transformou-se em um potencial artifício de dominação das massas.

Assim, os conteúdos inverídicos manipulam, dissimulam e desinformam milhões de pessoas através de sua massificação. De acordo com Gomes e Dourado (2019, p.33), o alcance de dada fake news está diretamente associado ao teor político dessa história. Para os autores, são os

\footnotetext{
2 UNESCO. (2019). Desinfodemia: decifrar a desinformação sobre a Covid-19. https://bityli.com/8Cvjo. Consultado em 2020, 23 de maio. Em diversos artigos usou-se a palavra "infodemia" para referir-se ao fenômeno de desinformação sobre a pandemia. No entanto, o termo infodemia não surgiu em decorrência da pandemia de informações em tempos de Covid-19. Infodemia já era um termo usado pela UNESCO para alertar sobre a "enxurrada de informações, precisas ou não, circulantes no meio". Todavia, o termo "desinfodemia" foi criado para descrever exclusivamente a epidemia de desinformações sobre a doença.
} 
atores, eventos e temas que conseguem mobilizar sentimentos e impulsionar engajamento mais do que outros, de modo que "é preciso prestar atenção aos atores políticos, à temática e ao viés adotado" (Gomes y Dourado, 2019, p.33) de uma determinada informação.

Engana-se quem pensa que as informações falsas são inofensivas. Somadas, elas compõem um arsenal de consequências gradualmente danosas, pois interferem diretamente nas dinâmicas sociais, podendo ser um risco às democracias modernas. Elaboradas em crenças pessoais e ideologias, geralmente de caráter emotivo e sem fundamentação científica, as informações falsas ganham a simpatia dos usuários, transformando-os em colaboradores desta proliferação. Lewandowsky et. al (como se cita em Amaral y Santos, 2019), sublinha que a emergência da era da desinformação, deve-se as "mega-tendências societais, como o declínio do capital social, a crescente desigualdade econômica, o aumento da polarização, o declínio da confiança na ciência e o crescimento gradual da fragmentação da paisagem mediática", em crises humanitárias, tais tendências se intensificam, assim como as informações inverídicas. Se em outros contextos, as informações falsas têm o poder de destruir reputações, em crises humanitárias como a da Covid-19, elas podem matar vidas.

\subsection{Crises humanitárias e a necessidade de informação}

Para Pena (2015, p. 22), o surgimento do jornalismo está ligado ao medo do desconhecido, à vontade de estar ciente sobre os acontecimentos. A necessidade de informação é inerente ao ser humano. Ela nos possibilita moldar nossas opiniões, organizar nossas ações e tomar decisões. Em crises humanitárias, essa necessidade de estar informado torna-se prioritária, urgente e imediatista.

Informação e comunicação são ferramentas essenciais para salvar vidas em uma resposta de emergência. Eles ajudam as comunidades em crise, permitindo que elas saibam o que está acontecendo ao seu redor, organizam, coordenam e identificam fontes de apoio e assistência. (Quintanilla, J. et al., 2014, p. 8).

A utilidade de informar e comunicar-se em contextos de crise, não se limitam somente para as pessoas que vivem naquela região, como também auxiliam e ajudam as organizações e instituições de ajuda a avaliar, mapear e identificar as necessidades que essas pessoas precisam e como podem assisti-las.

Como toda crise e situação são diferentes, é impossível apresentar uma visão abrangente desses desafios. Mas existem várias características comuns que costumam aparecer: falta de tempo para pesquisar e a urgência de necessidade imediata. Se as informações não forem abordadas rapidamente, elas podem aumentar muito o sofrimento, o que difere de uma situação normal (Quintanilla, J. et al., 2014, p. 31).

Daí a importância das informações verificadas e do jornalismo. No entanto, relatar uma crise humanitária, não é como relatar um acontecimento comum. É uma situação atípica, onde o tempo é curto, as informações são urgentes, a situação é frequentemente caótica e as emoções estão à flor da pele. O cenário traz "problemas e contextos específicos que os jornalistas precisam entender para poderem reportar de maneira eficaz e, ao fazer isso, apoiar suas comunidades" (Quintanilla, J. et al., 2014, p. 25). Por isso, o jornalista deve ser, sobretudo, fiel 
aos princípios deontológicos da profissão e cumprir com a sua responsabilidade social com o público, e principalmente com a verdade.

\subsection{A função social do jornalismo}

A desinformação é diferente do jornalismo - o verdadeiro jornalismo: ético, crível e de qualidade. No entanto, a linha entre as informações inverídicas e o jornalismo sensacionalista é tênue. Esse tipo de jornalismo é problemático, equivocado e anti-profissional e contribui para com o pandemônio da "desordem informacional", pois inclui erros contínuos, pauta deficiente com informações supérfluas, verificação malfeita, ausência de confronto entre fontes, linguagem dramática, parcialidade, entre outros.

Torna-se, assim, "evidente a necessidade de um jornalismo robusto e ético como uma possibilidade e um antídoto para a contaminação do ambiente da informação e o efeito indireto de degradação ampla de notícias" (Berger, 2019, p. 9). Simultaneamente, o jornalismo precisa ter uma abordagem contrária aos da desinformação, de modo que possa vir a ser "uma resposta imediata para um problema destrutivo, isto complementa e fortalece mais estratégias de médio prazo, como a alfabetização midiática e informacional, que capacita o público a distinguir o que é notícia, desinformação e informação incorreta" (Berger, 2019, p.20).

Na contemporaneidade, todos somos potenciais produtores de conteúdo, no entanto, durante crises humanitárias, a informação profissional se faz notável e precisa. No contexto pandêmico atual, a informação verificada é um dos bens mais valiosos, que só pode ser dado pelo jornalista.

Tendo em vista que a desinformação contribui para o descrédito da ciência, das instituições globais de saúde e da mídia, a pandemia e a circulação de informações equivocadas a respeito de sua natureza e seus efeitos, dá a certeza de que se vive um momento de máxima necessidade de valorização da comunicação organizada e corretamente realizada (Ferrareto y Morgado, 2020, p. 7-8).

O jornalismo de serviço torna-se mais relevante do que antes. A partir de fontes sérias, há que explicar e explicar novamente. A velha regra de não repetir conteúdos cai por terra. (...) É da redundância das boas práticas que vai se formar a compreensão do necessário para o enfrentamento da pandemia. (Ferrareto y Morgado, 2020, p. 17)

Por conseguinte, o jornalista tem um papel fundamental a desempenhar durante a pandemia, ele pode fornecer recursos através de abordagens utilitárias para a sensibilização da população mundial acerca dos dados, medidas preventivas, ações governamentais, programas de assistência, orientações médicas e afins, que possibilita às pessoas um entendimento da situação, viabilizando a tomada de decisões para proteger a si e seus familiares e ainda, o que esperar e como proceder no pós-crise.

Para maior compreensão da problemática, trouxemos a análise de episódios para ilustrar como a desinformação impacta gravemente a execução de ações de combate ao vírus, além de agravar crises internas e criar novos empecilhos para o enfrentamento da pandemia. Desse modo, o estudo segue uma abordagem qualitativa (Minayo, 2001, p. 21) reunindo pesquisa bibliográfica (Fonseca, 2002, p.32) e análise de conteúdo (Bardin, 1977, p. 34), pois o propósito central não está em quantificar um fenômeno, mas sim, compreendê-lo. Tal metodologia, de acordo com Bardin (1997, p. 42), visa obter "(por procedimentos sistemáticos e objetivos de descrição do conteúdo das mensagens) indicadores (quantitativos ou não) que permitam a inferência de 
conhecimentos relativos às condições de produção/recepção (variáveis inferidas) destas mensagens". Segundo Minayo (2001, p. 21), a pesquisa qualitativa trabalha com o universo de significados, o que corresponde a um espaço mais profundo das relações, dos processos e dos fenômenos que não podem ser reduzidos à operacionalização de variáveis.

\section{RESULTADOS}

A análise foi realizada a partir do conteúdo de textos que noticiam três episódios sobre informações falsas que circularam sobre o Covid-19, tendo como foco descrever os desdobramentos de tais episódios. No percurso da construção desse trabalho, encontramos centenas de casos sobre desinformação. Um estudo realizado pela The American Society of Tropical Medicine and Hygiene identificou 2.311 relatórios com conteúdo inverídicos, imprecisos e/ou manipulados sobre a Covid-19 em 25 idiomas de 87 países. A maioria dos rumores, estigma e teorias da conspiração foram identificados na Índia, Estados Unidos, China, Espanha, Indonésia e Brasil. Dito isso, nossa análise focou-se em episódios que ocorreram em dois países que aparecem nessa lista: China e Estados Unidos e, ainda, descreve os desdobramentos de um boato que levou centenas de pessoas à morte no Irã.

O critério de seleção adotado para a escolha dos episódios foi "a proporção de danos que uma informação falsa causou, tais como morte, internação, aumento do número de infectados". A coleta de textos para o corpus de análise foi feita por meio da ferramenta de pesquisa Google e das palavras-chave relacionadas: "fake news", "pandemia", "Covid-19", "coronavírus", "Trump", "Irã", "China" e "mortes". Na análise, buscou-se identificar o percurso cronológico das notícias publicadas em sites/portais brasileiros e estrangeiros sobre o compartilhamento das informações inverídicas sobre o vírus, durante o período de março a dezembro de 2020. A partir de exemplos concretos, foi possível discutir a problemática considerando o contexto social, político e cultural dos países onde tais informações foram compartilhadas. Foi possível também ilustrar os tipos de desinformação existentes e refletir sobre a importância dos processos de checagem, produção e socialização de conteúdos informacionais.

No quadro a seguir, elencamos para melhor visualização as manchetes dos textos analisados.

Tabela 1

Textos que compõem o corpus de Análise

\begin{tabular}{|l|l|l|l|l|}
\hline Autor & Título da Notícia & Portal & $\begin{array}{l}\text { Data da } \\
\text { Publicação }\end{array}$ & Fonte \\
\hline $\begin{array}{l}\text { Agence } \\
\text { France-Presse }\end{array}$ & $\begin{array}{l}\text { Após Fake News sobre cura da } \\
\text { Covid-19, 27 pessoas morrem } \\
\text { no Irã por ingestão de álcool } \\
\text { adulterado }\end{array}$ & UOL & $\begin{array}{l}\text { (2020, 09 de } \\
\text { março). }\end{array}$ & $\begin{array}{l}\text { Consultado em } 14 \text { de } \\
\text { março de 2020. }\end{array}$ \\
\hline $\begin{array}{l}\text { Agence } \\
\text { France-Presse }\end{array}$ & $\begin{array}{l}\text { Vinte e sete pessoas morrem } \\
\text { no Irã depois de beber álcool } \\
\text { adulterado para 'curar' o } \\
\text { coronavírus }\end{array}$ & GaúchaZH & $\begin{array}{l}\text { (2020, 09 de } \\
\text { março). }\end{array}$ & $\begin{array}{l}\text { Consultado em } 14 \text { de } \\
\text { março de 2020. }\end{array}$ \\
\hline
\end{tabular}




\begin{tabular}{|c|c|c|c|c|}
\hline $\begin{array}{l}\text { Redação } 0 \\
\text { Estado de São } \\
\text { Paulo. }\end{array}$ & $\begin{array}{l}44 \text { pessoas morrem de } \\
\text { intoxicação alcoólica no Irã por } \\
\text { acreditarem que bebida cura o } \\
\text { coronavírus. }\end{array}$ & Estadão & $\begin{array}{l}(2020,10 \mathrm{de} \\
\text { março). }\end{array}$ & $\begin{array}{l}\text { Consultado em } 17 \text { de } \\
\text { março de } 2020 . \\
\text { https://bit.ly/2NQNOot }\end{array}$ \\
\hline $\begin{array}{l}\text { Aranha, } \\
\text { Claudia. }\end{array}$ & $\begin{array}{l}\text { Fake news sobre coronavírus } \\
\text { leva } 44 \text { pessoas à morte no Irã }\end{array}$ & Exame & $\begin{array}{l}(2020,10 \text { de } \\
\text { março). }\end{array}$ & $\begin{array}{l}\text { Consultado em } 17 \text { de } \\
\text { março de } 2020 . \\
\text { https://bit.ly/2OfBEoO }\end{array}$ \\
\hline $\begin{array}{l}\text { Karimi, } \\
\text { Nasser y } \\
\text { Gambrell, } \\
\text { John. }\end{array}$ & $\begin{array}{l}\text { In Iran, false belief a poison } \\
\text { fights virus kills hundreds }\end{array}$ & $\begin{array}{l}\text { Associeted } \\
\text { Press News }\end{array}$ & $\begin{array}{l}(2020,27 \text { de } \\
\text { março). }\end{array}$ & $\begin{array}{l}\text { Consultado em } 30 \text { de } \\
\text { março de } 2020 . \\
\text { https://bit.ly/3kIDzOS }\end{array}$ \\
\hline $\begin{array}{l}\text { Aljazeera } \\
\text { Media } \\
\text { Network }\end{array}$ & $\begin{array}{l}\text { Iran: Over } 700 \text { dead after } \\
\text { drinking alcohol to cure } \\
\text { coronavirus }\end{array}$ & Al Jazeera & $\begin{array}{l}\text { (2020, } 27 \text { de } \\
\text { abril). }\end{array}$ & $\begin{array}{l}\text { Consultado em } 30 \text { de abril } \\
\text { de } 2020 . \\
\text { https://bit.ly/3sN6zrv }\end{array}$ \\
\hline AP News & $\begin{array}{l}\text { Fake coronavirus cure kills } 700 \\
\text { in Iran }\end{array}$ & $\begin{array}{l}\text { Washingto } \\
n \text { Times }\end{array}$ & $\begin{array}{l}\text { (2020, } 27 \text { de } \\
\text { abril). }\end{array}$ & $\begin{array}{l}\text { Consultado em } 30 \text { de abril } \\
\text { de } 2020 . \\
\text { https://bit.ly/3kI5HI3 }\end{array}$ \\
\hline BCC Research & $\begin{array}{l}\text { Coronavirus: Iran cover-up of } \\
\text { deaths revealed by data leak }\end{array}$ & $B C C$ & $\begin{array}{l}\text { 2020, } 03 \text { de } \\
\text { agosto) }\end{array}$ & $\begin{array}{l}\text { Consultado em } 05 \text { de } \\
\text { setembro de } 2020 . \\
\text { https://bbc.in/3sGLD5i }\end{array}$ \\
\hline Perez, Matt. & $\begin{array}{l}\text { Trump Suggests Injecting } \\
\text { Coronavirus Patients With } \\
\text { Light Or Disinfectants, } \\
\text { Alarming Experts }\end{array}$ & Forbes & $\begin{array}{l}\text { (2020, } 24 \text { de } \\
\text { abril). }\end{array}$ & $\begin{array}{l}\text { Consultado em } 15 \text { de maio } \\
\text { de } 2020 . \\
\text { https://bit.ly/3uUoyhM }\end{array}$ \\
\hline Star TV & $\begin{array}{l}\text { [vídeo] Trump suggests } \\
\text { injecting disinfectant as Covid- } \\
19 \text { treatment }\end{array}$ & $\begin{array}{l}\text { The Star TV } \\
\text { - Youtube }\end{array}$ & $\begin{array}{l}(2020, \quad 24 \text { de } \\
\text { abril). }\end{array}$ & $\begin{array}{l}\text { Consultado em } 15 \text { de maio } \\
\text { de } 2020 . \\
\text { https://bit.ly/30bREem }\end{array}$ \\
\hline $\begin{array}{l}\text { DALE, Daniel, } \\
\text { et.al. }\end{array}$ & $\begin{array}{l}\text { Trump sugere luz solar e } \\
\text { injeção de desinfetante para } \\
\text { tratar coronavírus }\end{array}$ & CNN Brasil & $\begin{array}{l}\text { (2020, } 24 \text { de } \\
\text { abril). }\end{array}$ & $\begin{array}{l}\text { Consultado em } 15 \text { de maio } \\
\text { de } 2020 . \\
\text { https://bit.ly/3b9tPKh }\end{array}$ \\
\hline $\begin{array}{l}\text { Sanders, Anna } \\
\text { y } \\
\text { Sommerfeldt, } \\
\text { Chris. }\end{array}$ & $\begin{array}{l}\text { A spike in New Yorkers } \\
\text { ingesting household cleaners } \\
\text { following } \\
\text { controversial } \\
\text { comments }\end{array}$ & Daily News & $\begin{array}{l}\text { (2020, } 24 \text { de } \\
\text { abril). }\end{array}$ & $\begin{array}{l}\text { Consultado em } 15 \text { de maio } \\
\text { de } 2020 \\
\text { https://bit.ly/2OfEQki }\end{array}$ \\
\hline $\begin{array}{l}\text { Guimón, } \\
\text { Pablo. }\end{array}$ & $\begin{array}{l}\text { "Por favor, não comam } \\
\text { pastilhas de detergente nem se } \\
\text { injetem nenhum tipo de } \\
\text { desinfetante", pedem médicos }\end{array}$ & El País & $\begin{array}{l}\text { (2020, } 25 \text { de } \\
\text { abril). }\end{array}$ & $\begin{array}{l}\text { Consultado em } 13 \text { de } \\
\text { junho de } 2020 \\
\text { https://bit.ly/3uKROHs }\end{array}$ \\
\hline
\end{tabular}




\begin{tabular}{|c|c|c|c|c|}
\hline $\begin{array}{l}\text { Zhao, } \\
\text { Christina. }\end{array}$ & $\begin{array}{l}\text { After Trump's Disinfectant } \\
\text { Comments, Calls to Poison } \\
\text { Control Centers Spike in New } \\
\text { York, Michigan, Illinois and } \\
\text { Maryland }\end{array}$ & NewsWeek & $\begin{array}{l}\text { (2020, } 26 \text { de } \\
\text { abril). }\end{array}$ & $\begin{array}{l}\text { Consultado em } 13 \text { de } \\
\text { junho de } 2020 \\
\text { https://bit.ly/3qmEiGR }\end{array}$ \\
\hline Wise, Justin. & $\begin{array}{l}\text { CDC warns against ingesting } \\
\text { hand sanitizer after reports of } \\
\text { poisonings, deaths }\end{array}$ & The Hills & $\begin{array}{l}(2020,08 \text { de } \\
\text { maio). }\end{array}$ & $\begin{array}{l}\text { Consultado em } 13 \text { de } \\
\text { junho de } 2020 \\
\text { https://bit.ly/3c3aAS5 }\end{array}$ \\
\hline Zachor, Emily. & $\begin{array}{l}\text { Texas Poison Control Blames } \\
\text { Online Misinformation for } \\
\text { Large Numbers of People } \\
\text { Drinking Bleach as Coronavirus } \\
\text { Cure. }\end{array}$ & NewsWeek & $\begin{array}{l}(2020,25 \mathrm{de} \\
\text { agosto). }\end{array}$ & $\begin{array}{l}\text { Consultado em } 02 \text { de } \\
\text { setembro de } 2020 \\
\text { https://bit.ly/3bflapU }\end{array}$ \\
\hline Conrow, Joan. & $\begin{array}{l}\text { What drove the Covid-19 } \\
\text { misinformation 'infodemic'? }\end{array}$ & $\begin{array}{l}\text { Cornell } \\
\text { Alliance for } \\
\text { Science }\end{array}$ & $\begin{array}{l}(2020,01 \text { de } \\
\text { outubro) }\end{array}$ & $\begin{array}{l}\text { Consultado em } 19 \text { de } \\
\text { outubro de } 2020 \\
\text { https://bit.ly/3qetieu }\end{array}$ \\
\hline Walsh, Nick. & $\begin{array}{l}\text { The Wuhan files: Leaked } \\
\text { documents reveal China's } \\
\text { mishandling of the early stages } \\
\text { of Covid-19 }\end{array}$ & CNN & $01-12-2020$ & $\begin{array}{l}\text { Consultado em } 04 \text { de } \\
\text { dezembro de } 2020 \\
\text { https://cnn.it/384vsXB }\end{array}$ \\
\hline
\end{tabular}

Fonte: elaboração propia.

\subsection{A epidemia dentro da pandemia: o surto de intoxicação alcoólica no Irã}

No dia 09 março de 2020, portais de notícias do mundo todo começaram a noticiar que vinte e sete pessoas morreram no Irã em decorrência de uma informação falsa sobre a cura da Covid19 que circulava no país. No Brasil, os principais portais que reportaram a notícia foram o $U O L^{3}$ e GaúchaZH $H^{4}$. De acordo com esses portais, um rumor de que a ingestão de álcool adulterado poderia imunizar e até mesmo curar a Covid-19 estaria sendo disseminado na República Islâmica do Irã.

Com a repercussão do boato no país, 27 pessoas vieram a óbito por intoxicação resultante do consumo de metanol. Do total de vítimas, 20 ocorreram na província de Khuzestan, localizada no sudoeste do Irã e as outras sete vítimas na província de Alborz, região localizada no oeste do país, próxima à capital Teerã. Ainda, as reportagens frisam sobre a legislação iraniana que proíbe o consumo e a venda de bebidas alcoólicas no país. Outro fator destacado é a posição que o Irã assumia quanto à progressão do novo coronavírus. Na época em que as notícias foram veiculadas, a República Islâmica era o terceiro país mais afetado pelo vírus no mundo com 237 mortes.

\footnotetext{
3 AFP; UOL. (2020, 09 de março). Após Fake News sobre cura da Covid-19, 27 pessoas morrem no Irã por ingestão de álcool adulterado. UOL Saúde. https://bit.ly/3rkTG7W

${ }^{4}$ APF; GaúchaZH. (2020, 09 de março). Vinte e sete pessoas morrem no Irã depois de beber álcool adulterado para 'curar' o coronavírus. GZH Mundo. https://bit.ly/3bearMs
} 
As informações contidas em ambos portais brasileiros foram apuradas pela Agência FrancePresse, agência global de notícias, e tinham como fonte a IRNA ${ }^{5}$, agência oficial iraniana. A partir desse episódio começamos a monitorar a progressão desta informação falsa. Assim, encontramos notícias publicadas um dia após a publicação dos primeiros óbitos por intoxicação pelo consumo de álcool adulterado. No dia 10 de março, portais de notícias brasileiros como o Estadão $^{6}$ e Exame ${ }^{7}$, noticiaram o aumento do número de mortos por ingestão de metanol no Irã, de 27 para 44 óbitos.

Segundo as informações dos portais, a província de Khuzestan ${ }^{8}$ foi a mais afetada com 36 mortos por intoxicação, o equivalente ao dobro de mortos pelo coronavírus na região na data de publicação. Além disso, outras 218 pessoas teriam sido hospitalizadas em decorrência da ingestão de álcool adulterado na cidade de Ahvaz, capital do Khuzestan. Novamente as informações noticiadas pelos portais foram apuradas pela AFP com fonte oficial da IRNA. Em 27 de março, portais de notícias internacionais voltaram a noticiar novas mortes por intoxicação alcoólica. Segundo a reportagem da Associeted Press News ${ }^{9}$, o número de óbitos subiu de 44 para cerca de 300 óbitos. O portal também noticiou que o número de pessoas internadas por intoxicação passava dos 1.000 casos na data de publicação. De acordo com a mídia iraniana, fonte oficial dos portais, outras cidades do país como Shiraz, Karaj e Yazd, começaram a reportar casos de envenenamento por metanol.

A reportagem, por sua vez, cita os principais danos causados pela ingestão de álcool adulterado, tais como náuseas, danos cerebrais, cegueira e coma. Com isso, os jornalistas descrevem a cena de um menino de cinco (05) anos entubado em um hospital em Teerã que ficou cego depois que seus pais Ihe deram metanol ao acreditarem na informação falsa. A reportagem aborda ainda aspectos sobre a ilegalidade da substância no Irã e as penalidades para quem consome e/ou vende, como multas em dinheiro e chibatadas. Outro fator que a notícia relata é a exigência do governo iraniano para os fabricantes de metanol adicionarem uma cor artificial em seus produtos para que a população possa diferenciar os tipos de álcool.

Mesmo com as investidas do governo em frear o boato, a informação falsa continuou repercutindo no país. Desse modo, um mês depois, no dia 27 de abril, portais estrangeiros como

\footnotetext{
${ }^{5}$ Mídia oficial do governo do Irã. The Islamic Republic News Agency. https://www.irna.ir

6 Redação, O Estado de São Paulo. (2020, 10 de março). 44 pessoas morrem de intoxicação alcoólica no Irã por acreditarem que bebida cura o coronavírus. Estadão Saúde. https://bit.ly/2NQNOot

${ }^{7}$ Aranha, C. (2020, 10 de março). Fake news sobre coronavírus leva 44 pessoas à morte no Irã. EXAME. https://bit.ly/2OfBEoO

8 Nos portais de notícias, a província aparece erroneamente com o nome de Juzestão. No entanto, a província chama-se Khuzestan (Cuzestão), cuja capital é Ahvaz no sudoeste do Irã.

${ }^{9}$ Karimi, N. y Gambrell, J. (2020, 27 de março). In Iran, false belief a poison fights virus kills hundreds. AP NEWS. https://bityli.com/tQOqB
} 
Al Jazeera ${ }^{10}$ e Washington Times ${ }^{11}$ noticiaram que o número de mortos por intoxicação no Irã passava dos 700. Assim, as notícias trouxeram a fala do porta-voz do ministério da saúde do Irã, Kianoush Jahanpour, que informou que 728 iranianos faleceram por intoxicação pelo consumo de álcool adulterado entre 20 de fevereiro e 7 de abril e, que neste período, 5.011 pessoas foram envenenadas por metanol. Dos intoxicados, 90 perderam a visão ou ficaram com algum dano ocular, todavia, Hossein Hassanian, conselheiro do Ministério da Saúde do país, disse que o número pode ser maior, em decorrência das pessoas que não procuraram as unidades de saúde.

Contudo, essa foi a última notícia que encontramos nos veículos de mídia brasileiros e estrangeiros sobre os danos causados pelo surto de intoxicação por metanol desencadeados pela informação falsa. Entretanto, diversos artigos e relatórios científicos sobre o consumo e intoxicação por álcool adulterado foram publicados posteriormente. Inclusive um deles tem como autor Hassanian, cujo artigo ${ }^{12}$ discorre sobre o "duplo problema" no Irã, uma epidemia dentro da pandemia como se pode descrever o surto de intoxicações.

Outrossim, o envenenamento de metanol não é um problema exclusivo da pandemia no país. Durante décadas, casos de intoxicação pelo consumo de álcool adulterado têm sido um desafio significativo para a saúde pública iraniana. Todavia, nunca antes a situação havia atingido números tão alarmantes como em 2020 por conta do boato disseminado. Segundo Hassanian (2020, p. 03), "o número de casos de envenenamento iraniano (5.876 hospitalizações do final de fevereiro até o início de maio), já é cinco vezes maior do que o segundo maior surto de metanol da história, que foi registrado na Líbia em março de 2013 e afetou 1.066 pacientes". Além disso, o impacto da desinformação foi tão grande que se espalhou pelo país inteiro e diversas províncias tiveram mais incidências de casos e mortes por intoxicação do que por Covid19 de fevereiro a abril de 2020.

No entanto, diversos fatores podem ter contribuído para que a situação ficasse fora de controle. O país já sofria tensões internas e diplomáticas desde o início do ano. Dessa maneira, a pandemia chegou em um momento crítico no país que passou a sofrer novas sanções econômicas, mergulhando, assim, em uma grande recessão e impedindo a compra e recebimento de medicamentos e EPI's para o enfrentamento da crise sanitária. Não obstante, o governo enfrentava uma série de manifestações populares que começaram por conta do aumento do preço de combustível e que logo fortificou-se em prol da democracia. Isso porque o país tem um regime ditatorial teocrático comandado pelos aiatolás, cuja governança é estritamente repressiva e ultranacionalista. O Irã é um dos países mais fechados do mundo, sustentando um dos regimes mais restritivos quanto ao acesso à internet e informações no mundo. Milhares de sites são bloqueados tais como portais de notícias e redes sociais. O país mantém uma operação estatal da mídia pela qual autoridades iranianas controlam a cobertura de determinados temas.

10 AP News. (2020, 27 de abril). Fake coronavirus cure kills 700 in Iran. The Washington Times. https://bityli.com/vZCW7

${ }^{11}$ Aljazeera. (2020, 27 de abril). Iran: Over 700 dead after drinking alcohol to cure coronavírus. Aljazeera Media Network. https://bityli.com/rQLzS

12 Hassanian-Moghaddam, H., et al. (2020). Double Trouble: methanol outbreak in the wake of the Covid19 pandemic in Iran - a cross-sectional assessment. https://bityli.com/yglOL 
Segundo o Comitê para Proteção aos Jornalistas ${ }^{13}$, o Irã é o sétimo país que mais restringe a imprensa, o segundo pior carcereiro de jornalistas e o país líder em prisões de jornalistas no mundo. A imprensa sofre censura e assédio do governo, resultando em informações não confiáveis por ambas as partes.

Uma reportagem investigativa da $B B C^{14}$ publicada em agosto, denuncia a omissão dos dados do governo sobre a situação no Irã. Segundo a reportagem, o número de mortos por Covid-19 é o triplo do que o número divulgado pelo governo em suas mídias oficiais. Nesse sentido, a desconfiança e a insegurança da população às ações do governo frente à pandemia e também a falta de informações precisas sobre o novo coronavírus, fez com que o medo e o pânico diante da situação pandêmica se tornassem um campo fértil para a propagação do rumor sobre uma cura milagrosa da doença. Podemos, assim, arriscar dizer que a informação falsa configura-se como "disinformation", com intenção de causar danos, uma vez que os perigos do consumo de metanol já eram conhecidos no país. O boato pode ter sido impulsionado por contrabandistas a fim de lucrar com a situação. Por outro lado, a omissão de informações também é um tipo de desinformação. A reação negacionista das autoridades iranianas sobre o vírus, pode ter retardado a adoção de medidas de controle. Em consequência, um mês após o primeiro caso divulgado oficialmente de infecção pelo SARS-CoV-2 no país, o Irã passou a ser o terceiro país mais atingido pela doença, ficando atrás somente da Itália e da China, tornando-se o país mais afetado do Oriente Médio até os dias atuais.

\subsection{Injeção de desinfetante: a fala de Donald Trump e suas reverberações}

No dia 23 de abril de 2020, o presidente dos Estados Unidos, Donald Trump, participou da tradicional coletiva de imprensa diária na Casa Branca sobre a situação da pandemia no país. Contudo, uma fala sugestiva feita por ele durante a conferência sobre possíveis tratamentos para o coronavírus com luz solar e desinfetantes tomou grandes proporções, retaliações e até danos. Com isso, a fala do presidente norte-americano não demorou a ser noticiada nos veículos de comunicação do mundo todo e disseminada em massa nas redes sociais, gerando preocupação à comunidade médica e científica internacional.

Assim, no mesmo dia, a revista Forbes ${ }^{15}$ publicou uma notícia narrando de forma resumida os principais acontecimentos da coletiva. De acordo com a notícia, o subsecretário interino de Ciência e Tecnologia do Departamento de Segurança Interna dos EUA, Bill Bryan, compartilhou algumas descobertas "emergentes" sobre a reação do vírus em diferentes temperaturas e superfícies, e a partir disso, Trump teria começado a sugerir ideias hipotéticas sobre o uso de luz ultravioleta e injeção de desinfetante para tratar o novo coronavírus. Todavia, a notícia não descreve precisamente os comentários proferidos por Trump na comitiva, apenas relata o

${ }^{13}$ Comitê para Proteção aos Jornalistas. 10 países que mais censuram. https://bityli.com/Zcbii

${ }^{14}$ BBC Research. (2020, 03 de agosto). Coronavirus: Iran cover-up of deaths revealed by data leak. BCC News, 2020. Disponível em: <https://bbc.in/3sGLD5i>.

15 Perez, Matt. (2020, 24 de abril). Trump Suggests Injecting Coronavirus Patients With Light Or Disinfectants, Alarming Experts. Forbes. https://bit.ly/3uUoyhM 
ocorrido. O vídeo da conferência, contudo, foi transmitido em canais de TV aberta e publicado em diversos sites, redes sociais e plataformas como Youtube, de modo que foi possível assistir a declaração exata de Donald Trump e compreender como se deu o desdobramento desta sugestão equivocada.

Suponhamos que expomos o corpo a uma tremenda quantidade de luz, seja ultravioleta ou só uma luz muito potente. Acho que você mencionou que isso não foi testado, mas você vai testá-lo. Então, eu digo, suponha que você põe a luz para dentro do corpo, o que pode ser feito através da pele ou de alguma outra maneira. Eu acho que você disse que vão averiguar isso também? Soa interessante. E veja o desinfetante, que consegue derrubar ele (o vírus) em um minuto. Um minuto! Existe alguma maneira de fazermos algo assim por injeção ou quase uma limpeza interna? Porque ele (o vírus) chega aos pulmões e atinge um número enorme de pulmões, então seria interessante você verificar isso e você vai ter que usar médicos, certo? Mas parece interessante para mim. (Trump, $2020)^{16}$

A $C N N^{17}$ noticiou em 24 de abril as primeiras manifestações de especialistas contestando a sugestão do presidente, inclusive da própria Organização Mundial de Saúde. Ainda no dia 24 de abril, o Daily News ${ }^{18}$ reportou o aumento de casos de intoxicação por ingestão de desinfetantes na cidade de Nova York após a fala de Trump. De acordo com o portal, cerca de 30 novaiorquinos teriam contactado as autoridades de saúde por administrarem desinfetantes e produtos de limpeza, nas 18 horas posteriores à declaração do presidente. A informação foi apurada pelo Daily News com base nos dados do Centro de Controle de Intoxicação, no entanto, não há nenhuma prova de que o aumento de casos tenha ligação direta à sugestão de Trump. Contudo, o número de casos de intoxicação por produtos de limpeza na cidade americana dobrou em relação ao mesmo período de 18 horas no ano passado. Segundo o Centro de Controle de Intoxicações foram apenas 13 casos envolvendo exposição a produtos domésticos em 2019.

Segundo o El País ${ }^{19}$, as autoridades de emergência do estado de Maryland receberam mais de cem chamadas de cidadãos perguntando se era possível tratar a Covid-19 com uso de desinfetante. Com isso, os serviços de saúde do estado emitiram uma nota orientadora para que a população não administrasse o produto em seu corpo. De acordo com o NewsWeek ${ }^{20}$, além de

16 The Star TV Channel. (2020, 24 de abril). Trump suggests injecting disinfectant as Covid-19 treatment. [vídeo]. YouTube. https://bit.ly/30bREem

17 Dale, Daniel, et.al. (2020, 24 de abril). Trump sugere luz solar e injeção de desinfetante para tratar coronavírus. CNN. https://bit.ly/3b9tPKh

18 Sanders, Anna y Sommerfeldt, Chris. (2020, 24 de abril). A spike in New Yorkers ingesting household cleaners following Trump's controversial coronavirus comments. NY Daily News. https://bit.ly/2OfEQki

${ }^{19}$ Guimón, Pablo. (2020, 25 de abril). "Por favor, não comam pastilhas de detergente nem se injetem nenhum tipo de desinfetante", pedem médicos. El País. https://bit.ly/3uKROHs

20 Zhao, Christina. (2020, 26 de abril). After Trump's Disinfectant Comments, Calls to Poison Control Centers Spike in New York, Michigan, Illinois and Maryland. NewsWeek. https://bit.ly/3qmEiGR 
Nova York e Maryland, Michigan e Illinois também tiveram um aumento nas ligações para seus centros de controle de envenenamento relacionados à exposição a produtos de limpeza doméstica nos dias seguintes às declarações de Trump.

Após a repercussão negativa da sugestão de Trump sobre a possibilidade de usar químicos nos pulmões de pessoas infectadas com coronavírus, o presidente tentou remediar a situação. Segundo o portal, Donald afirmou na comitiva do dia 24 de abril que sua fala teria sido "sarcástica". Contudo, mesmo com o esclarecimento do presidente e alertas da comunidade médica, os chamados de informação e números de intoxicação por produtos de limpeza doméstica continuaram. De acordo com o portal The Hills ${ }^{21}$, os Centros de Controle e Prevenção de Doenças $(C D C)$ divulgaram no mês de agosto um relatório que informa uma onda de intoxicações e quatro mortes entre maio e junho relacionadas ao consumo de desinfetante para mãos no Arizona e no Novo México. O relatório detalhou 15 casos de hospitalização por envenenamento pela ingestão de desinfetantes nos meses seguintes à fala do presidente. Destes 4 vieram a óbito, 3 tiveram sua visão comprometida.

O CDC do Texas também emitiu alertas sobre o uso indevido de alvejante doméstico e outros produtos de limpeza depois que a região norte do estado americano teve um aumento nos relatórios de pessoas que beberam desinfetante durante o mês de agosto, conforme apurado pelo NewsWeek ${ }^{22}$. Segundo a notícia, "o North Texas Poison Center, uma filial da agência de controle de veneno do estado, recebeu 46 ligações relacionadas à ingestão de alvejante desde 1 ㅇ de agosto". Além disso, a gerência de educação pública da instituição levanta a possibilidade dos casos de intoxicação terem uma relação direta com a disseminação de informações falsas. Outro dado relevante apresentado na reportagem é que o Texas Poison Center Network confirmou um aumento de $71 \%$ em chamadas a unidades de saúde e centrais de envenenamento envolvendo produtos de alvejante e $63 \%$ nas ligações envolvendo outros desinfetantes.

A incidência de casos de intoxicação pelo consumo de produtos de limpeza domésticos nos EUA já tinha se mostrado preocupante no início da pandemia. O CDC registrou nos três primeiros meses do ano um aumento de $20 \%$ em relação ao mesmo período em 2019 . A ideia simplista que partiu do senso comum, deteve-se na informação de que o vírus morre rapidamente ao ser exposto a substâncias desinfetantes, e com isso, acreditou-se que ao ingeri-las o resultado seria semelhante. Trump seguiu a mesma linha de raciocínio na comitiva.

No entanto, ao sugerir ao seu comité de especialistas em saúde pública que investigassem a possibilidade de usar a inserção destes químicos nos pulmões das pessoas infectadas, o presidente norte-americano cometeu um ato falho de irresponsabilidade. Enquanto figura pública e líder-mor dos Estados Unidos, sua fala não só reafirmou, como deu credibilidade a uma hipótese baseada no senso comum, oficializando, assim, a informação falsa que já estava sendo

21 Wise, Justin. (2020, 05 de agosto). CDC warns against ingesting hand sanitizer after reports of poisonings, deaths. The Hills. https://bit.ly/3c3aAS5

22 Zachor, Emily. (2020, 25 de agosto). Texas Poison Control Blames Online Misinformation for Large Numbers of People Drinking Bleach as Coronavirus Cure. NewsWeek. $\underline{\text { https://bit.ly/382parJ }}$ 
disseminada nas redes e potencializando-as. Consequentemente, o inequívoco trouxe diversas consequências tais como a disseminação em massa de informação falsa, o descrédito à ciência, intoxicações seguidas internações e até morte.

Um estudo feito pela Cornell Alliance for Science ${ }^{23}$ concluiu que Donald Trump foi possivelmente o maior impulsionador da desordem informacional sobre a Covid-19. A pesquisa avaliou cerca de 38 milhões de artigos publicados pela mídia tradicional de língua inglesa de todo o mundo, fazendo então uma análise sobre a cobertura midiática da desinformação relacionada à pandemia entre os meses de janeiro e maio deste ano. Desse modo, o estudo identificou onze tópicos mais proeminentes de conteúdos inverídicos relatados na mídia e analisou como se deu o engajamento desses tópicos desinformacionais nas redes sociais. Dos onze tópicos, pelo menos quatro tinham ligação com alguma fala proferida por Trump, representando 37,9\% da conversa de desinformação geral. No topo da lista de informações falsas, os conteúdos mais disseminados seriam sobre as supostas "curas milagrosas", em especial a declaração de Trump na coletiva do dia 24 de abril sobre as possibilidades do uso de desinfetante para o tratamento do vírus. Contudo, acredita-se que os impactos da declaração não foram maiores em decorrência da mobilização da comunidade médica e científica mundial em desmentir e alertar sobre os riscos da substância à saúde. Isso só foi possível por tratar-se de uma democracia.

Outro aspecto de suma relevância descrito no estudo foi o papel desempenhado pela mídia com a checagem dos fatos e correção de informações falsas. No entanto, ainda são poucos os veículos que estão engajados na luta contra a desinfodemia, pois apenas $16,4 \%$ de todo conteúdo inverídico disseminado foi corrigido pelos portais. Isso reforça o que pautamos nesse estudo: a responsabilidade social do jornalismo em apurar os fatos, informar de forma precisa e ética e, sobretudo, corrigir informações incorretas.

Dentro dos parâmetros da desinformação, a fala de Trump pode possivelmente ser ilustrada como uma mis-information, uma informação falsa sem intenção de causar danos, assim como pode se enquadrar como mal-information, uma informação incorreta e/ou má interpretada, uma vez que ele sugeriu e não afirmou a eficácia de tais substâncias no corpo humano como tratamento para a Covid-19. Todavia, não se pode isentá-lo da responsabilidade e danos ocasionados em sugerir, sem embasamento científico, a ingestão de algo tão perigoso. Como presidente da maior potência econômica mundial, suas ações e posicionamentos influenciam diretamente milhões de cidadãos em escala global. Por isso, é válido frisar que as mensagens públicas e de interesse público devem voltar-se para a conscientização sobre métodos de prevenção baseados em evidências, além de enfatizar práticas seguras de limpeza e desinfecção e os perigos tanto das substâncias quanto da desinformação.

\subsection{Os arquivos de Wuhan e a omissão de dados sobre o SARS-CoV-2}

Desde o início do surto epidêmico da Covid-19 na China, diversos países e instituições desconfiavam que informações estavam sendo omitidas pelo país asiático. Recentemente, a

${ }^{23}$ Conrow, Joan. (2020, 01 de outubro). What drove the Covid-19 misinformation 'infodemic'?. Cornell Alliance for Science. https://bit.ly/3qetieu 
equipe de jornalismo da $\mathrm{CNN}^{24}$ obteve documentos oficiais que comprovam que a China, de fato, ocultou a extensão inicial do surto de coronavírus. Em reportagem, a CNN aponta que as autoridades locais já tinham informações preliminares de uma possível epidemia no país por conta de um vírus desconhecido, entretanto, as informações e alertas às instituições de saúde foram divulgadas oficialmente vários dias depois. Para produzir a reportagem, a CNN afirmou que todos documentos foram verificados por seis especialistas independentes que examinaram a veracidade de seu conteúdo, contando com a confirmação de fontes e realizando uma análise forense digital para testar seu código de computador contra suas supostas origens.

De acordo com a CNN, "os documentos mostram uma ampla gama de dados em dois dias específicos, 10 de fevereiro e 7 de março, que muitas vezes estão em desacordo com o que as autoridades disseram publicamente na época". Com base em depoimentos de analistas, a reportagem aponta para a possibilidade de que a discrepância de dados tenha sido ocasionada pela "combinação de um sistema de relatórios altamente disfuncional e um instinto recorrente de suprimir más notícias", de maneira que optaram por não revelar ao público os dados e proporções reais da proliferação do vírus.

Com isso, os documentos mostram que a China omitiu cerca de $1 / 3$ dos casos de infecção pelo novo coronavírus no início da pandemia. Em 10 de fevereiro de 2020, a China divulgou que havia 3.911 casos registrados naquele dia, todavia, os documentos mostram um total diferente de 5.918 novos casos notificados no país. Ainda a reportagem levanta a possibilidade da omissão sobre o número de mortes provocadas pela doença, uma vez que em 17 de fevereiro, a China divulgou ter 93 vítimas fatais de Covid-19, no entanto, o documento descrevia 196 mortes até a data. Outro aspecto importante é que diversos especialistas avisaram as autoridades sobre o vírus desconhecido e seu potencial de transmissão humana, mas foram ignorados e até mesmo ameaçados e perseguidos de trazer a informação a público. No final de dezembro, por exemplo, um jovem médico chamado Li Wenliang que trabalhava em um hospital em Wuhan foi convocado pelas autoridades locais e recebeu uma "reprimenda" formal da polícia por tentar alertar sobre um vírus "semelhante ao SARS". Semanas depois, Li contraiu a Covid-19 e seu quadro agravou-se rapidamente, vindo a óbito na manhã de 7 de fevereiro.

Todavia, a reportagem destaca que "não está claro até que ponto o governo central estava ciente das ações que estavam ocorrendo em $\mathrm{Hubei}^{25}$ naquela época, ou quanta informação estava sendo compartilhada e com quem. Os documentos não oferecem nenhuma indicação de que as autoridades em Pequim estavam dirigindo o processo de tomada de decisão local".

Consequentemente, podemos elencar a problemática da omissão de informações como uma forma de desinformação, uma vez que o país escondeu informações de interesse público que poderiam antecipar ações, preparar outras nações e salvar vidas. Com isso, outros fatores devem ser levados em consideração nesta análise. Assim como o Irã, a China tem medidas restritivas bem duras, nas quais as informações são extremamente centralizadas e de difícil acesso, além do constante monitoramento da população. A perseguição a médicos, cientistas,

\footnotetext{
24 Walsh, Nick. (2020, 01 de dezembro). The Wuhan files: Leaked documents reveal China's mishandling of the early stages of Covid-19. CNN. https://cnn.it/384vsXB

25 Província chinesa cuja capital é Wuhan, onde surgiram os primeiros casos de Covid-19.
} 
profissionais da saúde e agentes da mídia que tentaram alertar para a gravidade do vírus, por exemplo, demonstra a barreira do fluxo de informações no país.

A pandemia iniciou em uma fase crítica para o país asiático. Na época, a China enfrentava uma crise de saúde por conta de um pico de gripe nas províncias de Hubei, Yichang e Xianning, o que pode ter dificultado a identificação do novo coronavírus. Além disso, a China também passava por uma crise econômica, resultado de sua guerra comercial com os Estados Unidos, contribuindo, assim, para a situação caótica de proliferação do vírus no país e, consequentemente, no mundo.

Por fim, ao investigar a fundo rumores sobre a omissão de dados das autoridades chinesas na fase inicial da pandemia, a reportagem da CNN demonstrou o comprometimento e a responsabilidade social que o jornalismo deve ter com a verdade e para com o público.

\section{DISCUSSÕES E CONCLUSÕES}

Em busca de respostas para a problemática da desinformação em um contexto de pandemia, nos desafiamos a descrever os desdobramentos da circulação de informações falsas sobre a Covid-19. Ao analisar os três episódios, identificamos danos causados por conteúdos inverídicos, incorretos, manipulados e ocultos. A falta de informações é um tipo de desinformação, pois deixa brechas para a criação de rumores e teorias conspiratórias que podem acarretar danos fatais, como ocorreu no Irã. A atitude da China em omitir, controlar e manipular dados não apenas criou um cenário desinformativo, como feriu gravemente o direito à informação em nível mundial. Já nos Estados Unidos, o excesso e o fluxo de informações circulantes é a ilustração perfeita do que a UNESCO chama de infodemia, cujos processos comunicacionais e, até mesmo jornalísticos, são prejudicados pela enxurrada de informações circulantes.

Todavia, chegamos a um dilema extremamente complexo em meio aos diferentes contextos políticos, sociais e culturais, e com isso, as divergências nas formas de governança e, principalmente, a singularidade na era da "pós-verdade". A reflexão que se faz é: até que ponto o acesso à informação é de fato informativo? E ao mesmo tempo, o que se pode fazer quando o controle de informações é um atentado aos direitos sociais, à liberdade de expressão e, sobretudo, à democracia?

A principal lição de todo esse pandemônio informacional durante a pandemia, é valorizar a informação profissional no pós-crise, entendendo a importância de informações precisas e verificadas. Nesse contexto, é preciso reconhecer os esforços de jornalistas que estiveram na linha de frente contra dois vírus extremamente letais: o SARS-CoV-2 e a desinformação. No entanto, a crítica também se faz presente: o jornalismo precisa cumprir com sua responsabilidade social seu dever com a verdade e com o público de forma ética.

A ressignificação do jornalismo se faz necessária, especialmente na era da desinformação. Repensar e incrementar ações que fomentem a educação midiática, voltada ao empoderamento cívico, à construção do pensamento crítico e à promoção da cidadania, são demandas urgentes para os processos comunicacionais e democráticos da contemporaneidade. 0 jornalista tem a responsabilidade social de educar seu público, assim como a mídia e as organizações governamentais promover um letramento de conteúdos a fim de instruir pessoas de todas as 
idades e classes sociais para serem consumidores mais críticos de conteúdo, além de capacitar o discernimento sobre informações falsas e verdadeiras, de modo que a população possa tomar decisões com base em fatos, e não em rumores.

\section{Referências}

Amaral, I. y Santos, J. S. (2019). Algoritmos e Redes Sociais: a propagação de fake-news na era pósverdade. (2019). En Figueira y Santos (Eds.), As Fake News e a Nova Ordem (Des)Informativa Na Era da Pós-Verdade: Manipulação, Polarização e Filter Bubbles (pp. 63-85). Coimbra University Press.

Bardin, L. (1977). Análise de conteúdo. Presses Universitaires de France.

Becker, B. y Goes, F. (2020). Fake News: uma definição possível entre a reflexão crítica e a experiência jornalística. Âncora, Revista Latino-americana de jornalismo, 7 (1), 1-20.

Berger, Guy. (2019). Jornalismo, Fake News e Desinformação: Manual para Educação e Treinamento em Jornalismo (pp. 7-14). Unesco.

Ferraretto, L. A. y Morgado, F. (2020). Covid-19 e Comunicação: Um Guia Prático para Enfrentar a Crise. Universidade Federal do Rio Grande do Sul. https://bit.ly/3bM7SRJ

Figueira, J., Santos, S. (2019). As Fake News e a Nova Ordem (Des)Informativa Na Era da Pós-Verdade: Manipulação, Polarização e Filter Bubbles. Coimbra University Press.https://doi: 10.14195/978989-26-1778-7

Fonseca, J. J. S. (2002). Metodologia da pesquisa científica. Apostila.

Gomes, W. y Dourado, T. (2019). Fake news, um fenômeno de comunicação política entre jornalismo, política e democracia. Revista Estudos em Jornalismo e Mídia, 16, (2), 33-45. https://doi: 0.5007/1984-6924.2019v16n2p33

Hassanian-Moghaddam, H., et al. (2020). Double Trouble: methanol outbreak in the wake of the COVID19 pandemic in Iran - a cross-sectional assessment. Crit Care, 24, 402 https://doi: 10.1186/s13054-020-03140-w.

Islam, M. S., et al. (2020). Covid-19 - Related Infodemic and Its Impact on Public Health: A Global Social Media Analysis. The American Journal of Tropical Medicine and Hygiene, 103 (4), 1621-1629. https://doi: 10.4269/ajtmh.20-0812

Minayo, M. C. S. (2001). Pesquisa social: teoria, método e criatividade. Vozes.

Pena, F. (2005). Teoria do jornalismo. Contexto.

Quintanilla, J., Hardman, J., et. al. (2014). Reporting on Humanitarian Crises: A Manual for Trainers \& Journalists and an Introduction for Humanitarian Workers. Organisation: Internews: Center of Innovation and Learning. https://bit.ly/30YvRqZ

Rezende, M. J. (2004). Linguagem Médica. AB.

Santana, G. P. y Simeão, E. (2019). Notícias falsas: origens, meios de disseminação, contextos e enfrentamento. En Seminario Hispano-Brasileño de Investigación en Información, Documentación Y Sociedad, (8). https://bit.ly/3vql6KB

Wardle, C., y Derakhshan, H. (2017). Information Disorder: Toward an interdisciplinary framework for research and policymaking. Council of Europe report. https://bit.ly/3eE1NbV

Wardle, C. et al. (2018). Information Disorder: the essential glossary. Harvard University. https://bit.ly/3liHqm0 


\section{Semblanza del autor/autores}

Bianca Cordeiro Manfrin é bacharel em Jornalismo pela Universidade de Cruz Alta/ UNICRUZ (2021), com passagem pela Universidade de Coimbra - Portugal, onde cursou um semestre da graduação em mobilidade acadêmica (2019). Foi bolsista pelo Programa de Iniciação Científica (PIBIC- UNICRUZ) vinculado à linha de pesquisa Linguagem, Comunicação e Sociedade. Tem experiência na área de Comunicação, com ênfase em Jornalismo, atuando principalmente nos seguintes temas: deontologia jornalística, desinformação, gênero e análise do discurso. Pesquisadora do Grupo de Estudos, Pesquisa e Extensão em Linguagens e Comunicação (GEPELC).

Dra. Veronice Mastella é doutora em Letras (Estudos Linguísticos) pela Universidade Federal de Santa Maria/UFSM (2015) com estágio doutoral com bolsa CAPES, na Universidade Pompeu Fabra (UPF), Barcelona (ES); Mestre em Comunicação Social pela Universidade Metodista de São Paulo/UMESP (2000); Especialista em Docência no Ensino Superior pela Universidade de Cruz Alta/ UNICRUZ (1999) e Bacharel em Comunicação Social - Habilitação Jornalismo pela Universidade Federal de Santa Maria/ UFSM (1984). Atualmente é professora adjunta da Universidade de Cruz Alta. Tem experiência na área de Comunicação, com ênfase em Cultura Midiática, atuando principalmente nos seguintes temas: mídia, cultura e sociedade; linguagem no contexto social; popularização da ciência; humanidades; jornalismo e rotinas produtivas. Pesquisadora do Grupo de Estudos, Pesquisa e Extensão em Linguagens e Comunicação (GEPELC). 